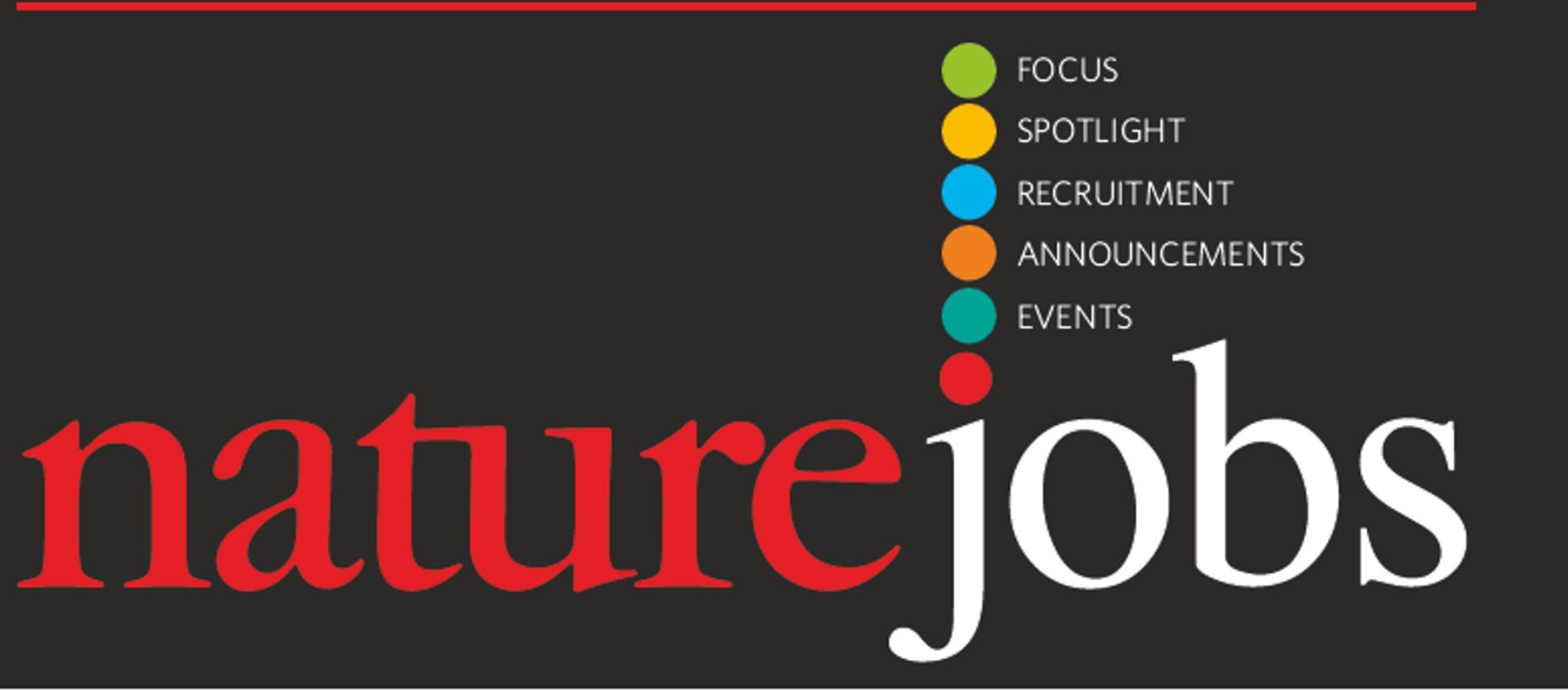

\title{
Fixing a broken record
}

During a recent holiday in northern California, I met a young scientist who was unsure about her graduateschool options. As an undergraduate, she worked in a really good developmental-biology laboratory, was interested in neuroscience, but was having difficulty getting a graduate position - despite some early publications and affiliation with a star of the field.

At this point, I slipped into a 'broken record' riff I've used at career fairs, round-tables and casual conversations this year. I told her to think of all possible career opportunities as a matrix. The vertical columns represent sectors and include academia, government and industry. The horizontal rows represent the broad disciplines of life sciences and physical sciences, with chemistry acting as an interdisciplinary interface between the two. Each 'cell' is divided into 'on the bench' and 'off the bench' jobs.

In this young scientist's case, for example, she might consider emphasizing biochemistry as a way to work her way into neuroscience. The supply-and-demand situation is better in chemistry, and straddling the disciplines allows more options in all sectors. Or she

CONTACTS

Publisher:Ben Crowe

Editor: Paul Smaglik

Marketing Manager: David Bowen

European Head Office, London

The Macmillan Building, 4 Crinan Street

London N1 9XW, UK

Tet +44(0) 207843496

$\mathrm{Fac}+44(0) 2078434996$

e-mall naturejobs@nature com

Naturejabs Sales Director:

Nevin Bayoumi (4978)

Europe an Sales Manager:

Andy Douglas (4975)
UK/RoW/Ireland//taly:

Nits Moeller (4953)

Irene Viglia-Alton (4944)

Scandinavia/Spain/Portugat:

Evelina Rubio Hakarsson (4973)

Natureevents:Sile Opstrup (4994)

Fance/Switzerland/Be lgium:

Amele Pequignot (4974)

Germany/Austria/The Netherlands:

ReyaSlso (4970)

\section{Advertising Production Manager:}

Bite franklin

To send maktetals use London

address above.

$\mathrm{Te} t+44(0) 2078434814$

might treat her technician post as a way to gain more skills, then switch sectors to pick up fresh techniques, before pursuing more formal training.

After the conversation, I reminded myself again that if I can talk this talk, then Naturejobs should walk this walk, by helping scientists representing all disciplines. In the past five years or so, we've included content that covers much of the grid - and a good part of the globe. Now, our relaunch of www.naturejobs.com will help readers navigate content and adverts by discipline, skill level and sector, as well as by geography through an interactive map. We are pleased to offer even more services, more direct contact with readers, and more opportunities for readers to participate in Naturejobs' own online matrix. And personally, I'm pleased to have found a way to fix my broken record.

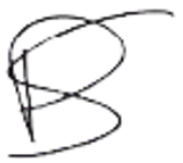

Paul Smaglik, Naturejobs editor

Fac $+44(0) 2078434996$

e-maitnaturejobs@naturecom

Natirejo bs web de velopment: Tom Hancock Naturejo bs online production: Niamh Shields

European Satelite Office

Germany/Austria/

The Netherlands:

Patrick Phelan

Tet +498954905711

Fac +498954905720

e-malip phelan@nature com

USHead Olfice, New York

345 Patk Avenue South.

10th Foo, New York.
NY 10010-1707

Tet +18009897718

$\mathrm{Fac}+18009897103$

e-mail nature jobsignaturen ycom

US Sales Manager: Peter Bless

Japan He ad Office, Tokyo

Chiyoda Bulling,

2-37 I higayatamachi,

Shinjukutku.

Tokyo 162-0843

Tet+81332678751

Fax +8133268746

Adia-Pacific Sales Director: Rinolo Asam:

e-mat rasamignaturejpncom 